\title{
Journal Aspirations: Improving Scientific Writing and Publication Through a Writing Mentorship Program
}

\author{
Ann Blair Kennedy, LMT, BCTMB, DrPH,
} Interim Executive Editor, IJTMB

University of South Carolina School of Medicine Greenville, Greenville, SC, USA

Looking to help novice scientific writers improve their skills and enhance the likelihood of scientific publication, the IJTMB launched a writing mentorship program. Research indicates that when novice writers have a mentor and work on writing as a team, the authors can gain selfefficacy, manuscripts are improved, thoughts and writing are clarified, and differing perspectives are added. This editorial identifies the process for being recommended to use a writing mentor, discusses recommendations in the forming of a mentor/mentee relationship, describes the qualities of good mentors and mentees, and offers suggestions for improving writing for scientific publication. As our database of writing mentors grows, we encourage those who join this program both as mentors and as mentees to consider what it means to be in these roles. It is my hope that the suggestions herein help in developing these relationships.

In my last editorial (March 2017), I announced the launching of the writing mentor program and how I have hopes that this program will help novice scientific writers become published here in the IJTMB in the future. Mentorship and writing as a team can help novice authors gain self-efficacy, improve the manuscripts, help to clarify thoughts and writing, and add differing perspectives in the scientific process. (1-3) In this editorial, I will identify the process for being recommended to use a writing mentor, discuss recommendations for the forming of a mentor/mentee relationship, describe the qualities of good mentors and mentees, and finally offer suggestions for improving writing for scientific publication.

Upon the submission to the Journal, there are times when manuscripts are identified as being on an interesting topic, yet in need of significant rewrites/ editing prior to and/or after peer review. For example, methods are not presented clearly, the introduction is not developed, or extraneous information is included. These are the manuscripts that are suitable for the writing mentor program. After a manuscript and author(s) have been identified, the editor will contact the authors to inform them of the issues with the manuscript, the impasse of moving the manuscript into peer review, and recommend the writing mentor program. If the authors agree to work with a writing mentor, the Journal's Executive Editor or Editor-inChief will contact the author and find an appropriate mentor based on level of mentoring need, topic, and availability. Introductions will be made electronically and then Journal staff will "step back" and allow the mentee and mentor to establish their relationship.

I suggest that the relationship begin with negotiations and clarification of expectations on both sides of the relationship. Discuss issues such as: How quickly will communication be returned? Will the mentor receive payment, authorship, or acknowledgement for their assistance with the manuscript? If authorship is offered, what will be the agreed-to order of the authors? Will the mentee be responsible for incorporating all suggested edits, or will the mentor assist in this effort? What happens if the mentee does not agree with the suggestions of the mentor? Who will submit the manuscript?

With these questions in mind, researchers have identified the qualities found in good mentors and those include having personal qualities such as compassion and selflessness, tailoring the support to the mentee, and keeping and making time for mentees and the project. ${ }^{(4)}$ The mentor needs to listen to, show respect for, and guide the mentee through the process, not simply impose their will on the manuscript. Additionally, mentees also have responsibilities in the relationship; they need to be flexible, be open to feedback, demonstrate an enthusiasm for learning, and respect the mentor's time and expertise/experience. ${ }^{(3)}$ The mentor/mentee relationship can succeed with appropriate communication, attention, honesty, trust, and clear expectations.

I also offer some suggestions as an editor for both mentors and mentees with regard to scientific writing and submitting to journals. First, become familiar with the scope of the journal to which you intend to submit your manuscript, know the audience who reads the journal and craft your manuscript for that audience. I also recommend that authors read other articles in the journal to become familiar with how 
the journal expects papers to be written and "sound". Next, cite those articles from the journal to which you will be submitting that will support your manuscript and advance your argument in your paper. Likewise, it is vitally important that you follow the author guidelines, including reporting and formatting guidelines. If a journal requires you to follow the CONSORT or CARE guidelines for your type of manuscript, make certain that you have included all those portions in your article. Lastly, it can be very helpful if you include some suggested peer reviewers for your article and include a brief explanation to the editors as to why each one would make a good reviewer (e.g., Dr. Smith has expertise in health behavior interventions and qualitative methods). Finally, Singh and Mayer ${ }^{(1)}$ offer clear strategies and a list of tools that can help in preparing manuscripts and working with writing teams in their open access article found in Biochemistry and Molecular Biology Education.

If becoming a writing mentor sounds appealing, please consider filling out our survey to help populate our database (https://goo.gl/forms/YidrbhotdHOcFUlk2). As our database of writing mentors is now growing, we encourage those who join this program both as mentors and as mentees to consider what it means to be in these roles and I hope these suggestions found herein will help in the development of these relationships. Finally, our one requirement for engaging in this service is this: if the relationship does result in a new publishable manuscript, that manuscript should first be submitted back to the IJTMB as a courtesy for helping to bring the manuscript to fruition.

\section{COPYRIGHT}

Published under the CreativeCommons AttributionNonCommercial-NoDerivs 3.0 License.

\section{REFERENCES}

1. Singh V, Mayer P. Scientific writing: strategies and tools for students and advisors. Biochem Mol Biol Educ. 2014;42(5): 405-413.

2. Lin P-Y, Kuo U-R. A guide to write a scientific paper for new writers. Microsurg. 2012;32(1):80-85.

3. Sanfey H, Hollands C, Gantt NL. Strategies for building an effective mentoring relationship. Am J Surg. 2013;206(5): 714-718.

4. Cho CS, Ramanan RA, Feldman MD. Defining the ideal qualities of mentorship: a qualitative analysis of the characteristics of outstanding mentors. Am J Med. 2011;124(5):453-458.

Corresponding author: Ann Blair Kennedy, LMT, BCTMB, DrPH, University of South Carolina School of Medicine Greenville, 701 Grove Rd., Greenville, SC 29505, USA

E-mail: kenneda5@greenvillemed.sc.ed 